\title{
Justice Health: Social Attitudes of Russian Patients in the Context of Availability
}

\author{
Zhanna V. Saveleva ${ }^{1}$, Ruzaliya M. Dasaeva ${ }^{2}$ \\ ${ }^{1,2}$ Kazan Federal University, Institute of Social and Philosophical Sciences and Mass Communications, Kazan, Russia, \\ 420008
}

Received: 21st October 2017 Accepted: 16th November 2017, Published: 31st December 2017

\begin{abstract}
The article looks into the problem of determining health equity. There is a conception in society that public health service should be based on the fundamental principle of justice. However, there is no unity of views how it should be realized either in the scientific community or among men in the street. In scientific discourse there are coexisting ideas about the validity of the definition that is focused on the three groups of interpretations: the liberal, distributive paradigm and the paradigm of possibilities. The first is characterized by the emphasis on the individual's personal responsibility, the second - by attention to the social determinants of health, the third highlights the ideal of creating equality of not health services and health benefits, but the opportunities to maintain the health. In recent years, the policy in the sphere of the health of Russia has been reoriented toward a liberal model. Using a semi-formalized interview in two subjects of the Russian Federation, the representatives of various socio-demographic groups were interviewed for the purpose of obtaining social ideas of the fairness of Russian health protection. It was possible to obtain information on social ideas regarding the justice of ensuring availability of health service in connection with the place of residence, age, gender, dependencies and others. The interpretations concerning the rendering medical services to the able-bodied unemployed were also analyzed, the conclusions about the attitudes toward equality in rendering medical services were made, which runs counter to the current discourse of power.
\end{abstract}

Keywords: Health, Justice, Equality, Availability of Health Service, Social Ideas.

\section{Introduction}

The situation in the sphere of health of Russians can be called unfavorable: in comparison with the developed countries, the indicators that characterize this area of the social sphere, such as life interval, sickness rate, mortality, show ill-being. One of the topics raised in this regard is the organization of health protection, health policy on the distribution of benefits for the optimal work of this subsystem of the Russian society. Under the conditions of transition to the market and modernization of public health, scientific and political discussions continue on the justice of health care and the availability of medical services for citizens. However, social ideas about the principles of its implementation, the need for availability of medical services for different categories of citizens vary both within the community of experts and among the population.

Social theory has developed several approaches to social justice. Among the various classifications, the most significant in the context of the recent transformation of the socio-political and economic system is the selection of liberal (or liberal-democratic) justice and social (distributive) model, for example, by Will Kymlicka [1]. In the Soviet period, social policy was built on the basis of the second approach to justice - more pronounced at the early stage, evolving on subsequent into the ideas about equality of opportunities [2]. Under the existing situations of Russia, the discourses of the authorities on fair health migrate towards the liberal model: an information and political agenda is being formed, which states that health resources are more equitably distributed in favor of those who are more responsible for their health and do not risk it, have done a great service before society, have made a contribution to it, are more important (for example, they do not have shadow incomes, make transfers to the fund of compulsory health insurance) [3].The issues about priority models is in keeping with the discussion taking place in other countries with a market economy. Some researchers problematize the situation concerning the injustice of the equal distribution of medical services between those whose health suffers as a result of individual actions and irresponsible behavior, whether it is alcohol consumption [4], risky hobbies and sports, etc. [5]. Another part of the scientists points to the determining importance of social conditions, to the ability of being responsible [6], the influence of social factors on the choice of lifestyle, habits [7].The expansion of a new health paradigm is associated with the interests of political actors to reduce the price of health care [8]. The critics of the paradigm argue that healthism becomes an ersatz-religion and veils the problem of inequality [9].

One can identify an approach or a paradigm of equality of opportunity among the extreme forms of the distributive and liberal models of health equity. Justice as the ensuring of the choice does not preclude the actualization of such ideas as equality, consideration of personal success in the distribution of benefits, but at the same time, the real effective opportunities that people have for the choice in life, including choosing a way of life in the context of health $[10,11]$.

Thus, scientific models of equitable health care receive different interpretations - liberal, distributive, the 
approach of equal opportunities. However, any models of social policy cannot be realized without taking into account the normative-value system of social groups and social ideas of the population about justice. Ordinary conceptualization of justice and availability of health service became the object of sociological research.

\section{Methods}

During the study, we conducted a semi-formalized interview with representatives of different sociodemographic groups in the two constituent entities of the Russian Federation, the Republic of Tatarstan and the Republic of Mari El. The first is one of the most prosperous regions of Russia, the second economically challenged. In the capitals and districts for individual and focus group interviews during 2016, 131 informants were involved in total. This article presents a part of the study.

\section{Results}

The equality paradigm implies the equality of availability of medical services for residents of different regions and districts of the subjects of the RF. The informants of towns and urban-type settlements indicated no less availability of medical services in comparison with capitals and cities. "Unfortunately, the trend [of improving public health] is observed in large cities, little is being done for small rural hospitals". (Informant 1, the RME, urban-type settlement, 23 years old, woman). "We in small towns have lack of specialists, equipment for diagnosing various diseases. We have to go to neighboring republics, we have to pay, it is very difficult to get a quota for an operation, we have to beg for an appointment card for checkup".(Informant 2, the RME, village, 51, woman).

Here, according to the informants, there is a shortage of specialists and medical equipment: "We have lack of qualified doctors. Here is the main problem. All the doctors are of retirement age, and there are no young doctors". (Informant 4, the RME, medium-sized city, 31 years old, man). At the same time, the informant points out to the dependence of getting medical treatment using $\mathrm{CHI}$ for his illness, depending on the subject of residence, which he assesses as an injustice of the system: "Some republics (I exactly know in Bashkortostan) that they cannot make out a diagnose of our illness ... And that is how long we fought for our rights in Mari El, well, we have finally tried to get it, in hospital we have been our medicines dropped for 2 months. A girl from Bashkiria does not get medical service, and now she has registered in Tatarstan to undergo medical treatment ... And if you do not get your medicine dropped (such type of a disease), you can die simply from any infection, because you have no immunity". (Informant 4, the RME, medium-sized city, 31 years old, man).

Availability in connection with the gender received various interpretations among the informants interviewed. On the one hand, the majority of interviewees described the situation of equal opportunities of receiving medical care between men and women. On the other hand, some complained about the unavailability of narrow specialists in both women's and men's diseases. "The case is not good with narrow specialization, because, for example, to seethe mammologist, we need to turn .... Well, I myself, I go to the doctor directly once a year, but I necessarily go privately, consultations are paid in the state polyclinic, because it's problematic to get free consultation, there are no referrals, anything. And I have to go first to my therapist and if he allows, he will send me to the surgeon, and if the surgeon thinks it necessary, he will send me to the mammologist. And I, a woman, believe that I should be followed up by a doctor once a year. I go privately to public clinic for paid examination once a year". (Informant 8, the RT, big city, woman, 51 years old)."I think that special needs are almost not taken into account, at least, here the only gynecologist works in our hospital, and we do not have the doctor for men, surgeons perform some functions".(Informant 1, the RME, urban-type settlement, 23 years old, woman).

The issues about the necessity for free medical services for addicted people have found different variants of interpretation. Mostly, the informants spoke in favor of providing medical service to people with alcohol and drug addiction. "Of course, there must be [medical services]. Of course, it's free. Well, where does an alcoholic have money?"(Informant 4, RME, mediumsized city, 31, man). Some informants considered it a fair measure for people who are alcohol and drug addicted to take a single treatment: "I think that such people should get free treatment for the first time, but if you broke down, one is to charge a certain amount". (Informant 2, the RME, village, 51, woman).But to determine the necessity for free services for people with food addiction and obesity was difficult. "Obesity ... I'm exactly at a loss for answering ... And what about prevention: calls for a healthy and active lifestyle? Perhaps I have not encountered. Unpaid ... Let's say so, it is desirable, but not so necessary as with alcoholism, etc."(Informant 10, the RT, big city, woman, 34 years old).Some refused to attribute these addictions to the category of diseases requiring the distribution of general health resources: "We must keep the diet and make it our rule ... You should manage to learn somehow about obesity by yourself ... You ought to eat less".(Informant 4, the RT, capital, woman, 66 years old).

The ideas about the need for free course of treatment for smoking were differentiated. Some informants believed that treatment for alcohol and tobacco addiction should be undergone within the framework of special services for the CHI policy (free of charge): "It must be, of course!" Informant 5, the RME, village, 68 years old, man). The others said that such addiction is a zone of personal responsibility, in this connection, the individual ought to pay for medical care to get rid of it: "I believe this is a purely personal headache. You are your own enemy, not others'. And if you want to be treated for addiction, then you must pay 
yourself".(Informant 4, the RME, medium-sized city, 31 years old, man).

The informants were asked a question, discussed in the political space, about the justice of introducing a payment for a medical policy for the category of ablebodied Russians who do not officially work and do not make transfers to the fund of compulsory medical insurance, but receive medical aid in the system of public health care. Virtually all interpretations of the informants treated this measure as unacceptable: "For example, he cannot enter a job, circumstances are different. Well, at least he is anyone you like. It does not matter at all. It's unfairly", "No, it's unfairly, let everyone get medical aid provided", "Medical service must be rendered to everyone!"(Focus-group 1, the RME).The informants gave arguments for their standpoint, referring to humanism, to the need for mutual help in a civilized society: "But they [the unemployed citizens] are also people. We should help them (laughing). Even if they do not make transfers to the funds, they should have some minimum assistance provided. We are not animals. We should help each other". (Informant 3, the RME, medium-sized city, woman, 30 years old).Part of them, in addition, pointed to the impossibility of implementing this measure by virtue of the current legislation - Article 41 of the Constitution of the RF guarantees the citizen the right to health care and medical assistance: "And you will not take a penny from him ... you will not give him medical care, he will go and complain. Anyway, you will provide it and there is no getting away from it if we live in a humane society". (Informant 4, the RME, medium-sized city, 31 years old, male). The refugee from Ukraine lamented over great difficulties of finding official placement, wherever an employer would make transfers to social funds: “... And now, by my own bushel, now I would measure this situation differently, negatively, because stateless persons are not waited for at all with open arms: we are faced with this [...] and yes, they are glad to see me until they have learnt about my citizenship ... Therefore if I had to buy a policy, I would probably try to do without it at all, in extreme cases, I would go to private clinics. Taken by and large ... this is a terribly unfair measure". (Informant 10, the RT, big city, woman, 34 years old).

Regarding age groups, the respondents mainly pointed to the need to maintain the availability of medical services for children and the elderly people. In particular, injustice was defined by one of the informants as an appeal to the insufficient attention of the system to this category of citizens: "No, probably, an unfair [Russian health care], if it takes so little care of its people, its pensioners and its children ... probably , this is no longer fair in relation to its citizens".(Informant 8, the RT, capital, woman, 51 years old).

“... The elderly are generally taken care of not well". (Informant 7, the RT, capital, woman, 48 years old). "We have a well-developed medical care for pensioners in hospital. For them, separate equipped wards are allocated there, there are some privileges for veterans"..(Informant 1, the RME, village, 23 years old, woman). Although the assessments of medical care for the elderly, as we can see, may vary, the process of problematization of the need for special attention from health service to this category of the citizens will burn to testify that this characteristic is an essential attribute of the concept of justice: "But pensioners should have it [health care] provided. They have earned it. By their own labor they have earned this pension. They have lived all their lives in Russia, worked for Russia - they qualify or medical care”. (Informant 4, the RME, medium-sized city, 31 years old, man).

The people of active working-age talked about difficulties in availability of free medical services of the Russian health care system under the CHI program. The queues, uncomfortable reception hours for working citizens force them to go to medical institutions only in case of acute necessity: "I had to adjust after work, and even to leave work. And all the same, the therapist saw me not on time, I had to wait about forty minutes [...]. The therapist did not help [...] He thought a little and then he administered an additional examination in different parts of the city, which also needed to be registered, and something was paid, something was free. Including stomach evaluation, and it was necessary to have some complete count done on and look for polyclinics. The nurse was explaining for ten minutes how to find it and how the procedure is called ... something was written down. But, it's been several weeks now, and I have never found a place where it's done, nor have I remembered the procedure and nor have I quite understood what this examination is for". (Informant 11, the RT, capital, man, 28 years old). A similar situation among the informants of young and middle working age is typical and found in several interviews among the informants of both Tatarstan and Mari El. However, not all the informants perceive it as unfair. The economic status of this category of population is more favourable than of the older people and allows, if necessary, to use paid services. Some representatives of the younger generation consider paid services as a sign of the movement of the Russian healthcare system towards justice: "I think [Russian healthcare is fair]. It is especially useful that there are paid centers where you can go to without spending time on a simple queue. The only thing, it might be more equitable to bring down the cost of paid services. Well, and pay good salaries to the doctors in free clinics". (Informant 8, the RME, capital, man, 24 years old).

\section{Summary}

Social perception of the social justice of health protection has different interpretations among the population. Special categories of the population, singled out by the respondents as those who need for moderateness to medical services, are the elderly and children. The residents of small towns and villages expressed particular concern over the injustice of access to medical services, comparing themselves with the inhabitants of large cities. This is consistent with the report data of the Levada Center, which notes that it 
is the inhabitants of small towns and villages who encounter the main difficulties with availability of medical care (only one in ten notes about its increase for the last five years) [12].

Unemployed able-bodied citizens (and those who possibly lead an antisocial way of life, and those who have shadow employment and do not transfer funds to the CHI foundation) should also receive medical services in the healthcare system according to the results of the interview. For more substantiated and reliable conclusions, a mass poll is required, but our assumption is consistent with the data of the study of the notion of fairness based on the materials of 29 countries of the world by O.Karaeva, according to which in Russia there are expressed attitudes towards equality in health care without differentiation of medical care by the criterion of individual responsibility for problems with health: "The Russian population defends the inviolability of equal access to a full range of medical services at public expense" [13].

\section{Conclusion}

The modernization of public health services and power discourse, conducted in recent years in Russia, are oriented towards the liberal model and the economic logic of efficiency, which runs counter to the social ideas of the citizens - consumers of medical services about the principles of fairness of Russian healthcare, which escalates the situation of dissatisfaction with the organization of the system of health care. The results of these interviews make it possible to identify the repertoire of possible interpretations of justice and become the basis for a formalized mass survey by questionnaire.

\section{Acknowledgements}

The work is performed according to the Russian Government Program of Competitive Growth of Kazan Federal University.

The article was prepared with the financial support of the Russian Foundation for Basic Research (Grant №16-03-00579a“'Social justice and equity in a health care: experts' views, mass-media discourse and people's attitudes").

\section{References}

1. Kimlika U. Modern Political Philosophy. Introduction. M.: Economic Higher School Publishing, 2010 .

2. Chernysh M.F. Social Justice and Its Mirages// The World of Russia. 2012. № 2. P. 111.

3. To reach police. The unemployed can be offered to pay the rest of medical treatment instateclinics// Russian Newspaper. 2014. July 15.

4. Albertsen A. Drinking in the last chance saloon: luck egalitarianism, alcohol consumption, and the organ transplant waiting list // Medicine, Health Care and Philosophy. 2016. 19(2) P. 325-338.

5. Walker $\mathrm{T}$. Who do we treat first when resources are scarce? // Journal of applied philosophy. 2010. 27(2). P. 200-211.
6. Brown R.C.H. Moral responsibility for (un)healthy behavior // Journal of Medical Ethics. 2013. doi:10.1136/medethics-2012-100774

7. Buyx A., Prainsack B. Lifestyle-related diseases and individual responsibility through the prism of solidarity // Clinical Ethics.2012. 7(2). P.7985 .

8. Crawford R. Cultural influences on prevention and the emergence of a new health consciousness. // Taking Care: Understanding and Encouraging Self- Protective Behavior. Cambridge: Cambridge University Press, 1987. P. 95-113.

9. Gvozdev M.G. Health is min the Context of Criticism of Social Medicine // Society: Philosophy, History, Culture. 2016. №9. P.80-81.

10. Sen A. The idea of justice. L.: Penguin books, 2010 .

11. Ruger J.P. The health capability paradigm and the right to health care in the United States // Theoretical Medicine and Bioethics. 2016. -37(4). Pp.275-292.

12. "Confrontation of Logics": Doctor, Patient and Power under Conditions of Reforming the System of Health Service/ Free Analytical Return of LevadaCenter 2016. URL: http://www.levada.ru/cp/wpcontent/uploads/2016/05/299 1-15_Svodnyjanaliticheskij-otchet.pdf (accessdate 30.06.2017)

13.

Arayeva O. Ideas of Justice and Effectiveness in the Systems of Health Protection in Different Countries (According to data of ISSP) // Herald of Public Opinion. - 2014. - № 1/2 (January-June). URL: http://www.levada.ru/sites/default/files/vom_12_2014.pdf (access date 30.06.2017) 